\title{
End-to-side anastomosis in complex tracheal resection and reconstruction: a case series study
}

\author{
Jiaxi He ${ }^{1,2 \#} \wedge$, Xin $\mathrm{Xu}^{1,2 \#}$, Lan Lan ${ }^{2,3 \#}$, Hanzhang Chen ${ }^{1,2}$, Jianxing $\mathrm{He}^{1,2}$, Shuben $\mathrm{Li}^{1,2}$ \\ ${ }^{1}$ Department of Thoracic Surgery, the First Affiliated Hospital of Guangzhou Medical University, Guangzhou, China; ${ }^{2}$ National Clinical Research \\ Center for Respiratory Disease, Guangzhou Institute of Respiratory Disease, Guangzhou, China; ${ }^{3}$ Department of Anesthesiology, the First Affiliated \\ Hospital of Guangzhou Medical University, Guangzhou, China \\ Contributions: (I) Conception and design: Jiaxi He, S Li; (II) Administrative support: H Chen, Jianxing He, S Li; (III) Provision of study materials or \\ patients: X Xu, L Lan, H Chen, S Li; (IV) Collection and assembly of data: Jiaxi He, X Xu, L Lan; (V) Data analysis and interpretation: Jiaxi He, X \\ Xu, L Lan; (VI) Manuscript writing: All authors; (VII) Final approval of manuscript: All authors. \\ \#These authors contributed equally to this work. \\ Correspondence to: Shuben Li, MD, PhD; Jianxing He, MD, PhD. Department of Thoracic Surgery, the First Affiliated Hospital of Guangzhou \\ Medical University, Guangzhou, China. Email: 13500030280@163.com; hejianxing@hotmail.com.
}

\begin{abstract}
Background: The development of current anesthetic and surgical techniques has increased the success rate of complex tracheal resection and reconstruction. End-to-end anastomosis is the prevailing method, while the end-to-side approach has also been reported to be practical and suitable. The current study aimed to demonstrate the feasibility and advantages of the end-to-side anastomosis method in specific cases.

Methods: We summarized 6 cases of patients with tracheobronchial tumors who received different end-toside airway reconstructions in our center. Their clinical features and surgical procedures were also described. Postoperative follow-up was conducted to monitor their complications and prognosis.

Results: Among the patients involved in the study, 2 patients with tumors involving the bronchus intermedius received auto-lung transplantations under general anesthesia, 3 patients with tumors involving the lower trachea and carina underwent reconstruction under non-intubated combined anesthesia, and 1 patient with left main bronchus (LMB) involvement received surgery under venoarterial extracorporeal membrane oxygenation (VA ECMO)-supported non-intubated anesthesia. The surgical procedures were completed successfully without surgical or anesthetic incidents. Patients 1 and 2 underwent auto-lung transplantation with distal stumps and trachea end-to-side anastomosis (right lower lobe and right basal segment). Patients 3 and 4 received right main bronchus (RMB) to lateral trachea reconstruction, while Patients 5 and 6 underwent LMB to tracheal wall anastomosis. Anastomotic buttressing was performed using the thymus and mediastinal tissue. The patients were discharged within 2 weeks of the operation. No severe postoperative complications were reported, with the exception of Patient 5, who required a prolonged intensive care unit (ICU) stay with antibiotics due to pneumonia. Anastomotic necrosis, dehiscence, or stenosis were not observed in the postoperative bronchoscopy.
\end{abstract}

Conclusions: End-to-side anastomosis is a feasible and effective surgical method in airway reconstructions. This method facilitates tension-free anastomosis, which is crucial for surgical prognosis and decreasing complications. The reported cases had ideal surgical results during follow-up. The long-term outcomes of the end-to-side method require further evaluation.

Keywords: Trachea; reconstruction; anastomosis; end-to-side; case series

Submitted Nov 02, 2021. Accepted for publication Feb 16, 2022.

doi: $10.21037 /$ tlcr-22-32

View this article at: https://dx.doi.org/10.21037/tlcr-22-32

^ ORCID: 0000-0003-2726-6629. 


\section{Introduction}

Tracheobronchial tumors are rare, accounting for only $2 \%$ of airway malignancies, with squamous cell carcinoma and adenoid cystic carcinoma being the most common pathological types $(1,2)$. Patients primarily present with hemoptysis, irritative cough, and dyspnea on exertion (DOE). Bronchoscopic ablation and endotracheal stent application are reported to be effective in alleviating symptoms. However, these approaches are not curative, and patients may develop tumor recurrence or distant metastasis. Tracheobronchial resection and reconstruction are considered a radical approach for treating airway tumors but is reported to be effective in lowering the recurrence rate (3-5).

Surgical approaches for tracheobronchial tumors are various and customizable depending on the anatomic characteristics and complexities of the malignancies. Endto-end tracheobronchial anastomosis is the most commonly used method in airway reconstruction and is direct and easy to manage. However, this method is unsuitable or inappropriate in specific cases, including cases that involve incompatible stump diameters, high anastomotic tension, or trimming difficulties. Therefore, the end-to-side anastomosis method was introduced to facilitate tensionfree anastomosis and simplify the anastomosis process (6). In this paper we report 6 cases of tracheobronchial malignancy that were treated with different end-to-side airway reconstructions, with the aim of describing the end-to-side anastomosis surgical procedure and illustrating its utility and feasibility in specific cases. The detailed information of the patients was demonstrated in Table 1. We present the following article in accordance with the AME Case Series reporting checklist (available at https://tlcr.amegroups.com/ article/view/10.21037/tlcr-22-32/rc).

\section{Methods}

\section{Patients}

\section{Patient 1}

A 51-year-old female presented with a refractory irritative cough and bloody sputum for 2 months. The chest computed tomography (CT) scan showed a $4 \mathrm{~cm} \times 5 \mathrm{~cm}$ irregular mass in the right main bronchus (RMB) with hilar and mediastinal lymph node enlargement. The bronchoscopy showed an RMB tumor with a rough surface extending to the bronchus intermedius and occluding most of the bronchus intermedius lumen, with involvement of the superior segmental bronchus orifice. The biopsy indicated squamous cell carcinoma (Figure 1A). Positron emission tomography (PET) and CT scan confirmed no distant metastasis. We intended on performing a right and middle sleeve lobectomy, but noticed tension of the inferior pulmonary vein and a significant gap between the bronchial stumps during the procedure. We therefore performed a right basal segment auto-lung transplantation, in which the distal inferior pulmonary vein and artery were reconnected to the stumps of the superior vein and artery. The airway reconstruction was completed using an end-toside anastomosis between the basal segmental bronchus and the lateral tracheal wall via right thoracotomy.

\section{Patient 2}

A 41-year-old male presented with an irritative cough and DOE for 1 month. The CT scan and bronchoscopy showed an $8 \mathrm{~cm} \times 10 \mathrm{~cm}$ broccoli-like tumor in the bronchus intermedius involving the distal RMB (Figure 1B). The biopsy indicated squamous cell carcinoma, and the orifice of the superior segment bronchus was negative. The patient's intraoperative condition was similar to Patient 1 in that the tension of the inferior pulmonary vein was noticed when the reconstruction was about to start. A right lower lobe auto-lung transplantation was performed using an endto-side anastomosis between the lower lobe bronchus and the lateral tracheal wall. The distal stumps of the inferior pulmonary vein and lower lobe pulmonary artery were anastomosed to the proximal superior pulmonary vein and the upper lobe pulmonary arterial stump.

\section{Patient 3}

A 40-year-old female presented with bloody strips in the sputum and a cough for 1 month. The CT scan and bronchoscopy indicated a $3.0 \mathrm{~cm}$ irregular mass on the carina involving the orifice of the RMB with mediastinal lymph node enlargement (Figure 1C). A carinal resection and reconstruction were performed using uniportal videoassisted thoracic surgery (VATS) via a $3.5 \mathrm{~cm}$ incision in the fourth intercostal space on the right anterior axillary line. The carina and the $2-\mathrm{cm}-$ long RMB were resected with a negative margin. The left main bronchus (LMB) distal stump was reconnected to the tracheal stump using the end-to-end method. After releasing the right inferior pulmonary ligament and the right hilum, the RMB stump was reconnected to the lateral tracheal wall to facilitate a tension-free anastomosis. The final pathological result indicated epithelial-myoepithelial carcinoma, a very rare malignancy. 
Table 1 The profile of the patients with tracheobronchial malignancies who received resection and end-to-side anastomotic reconstruction

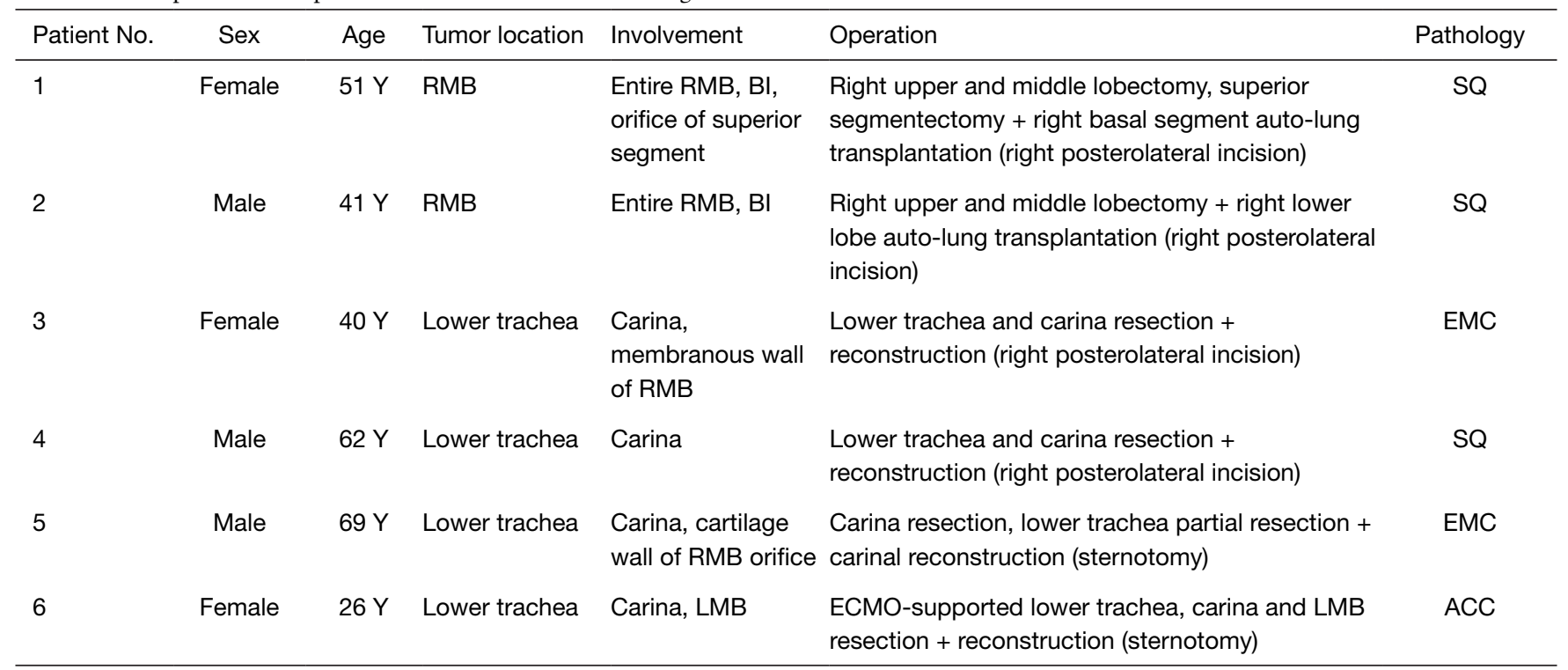

$\mathrm{RMB}$, right main bronchus; $\mathrm{BI}$, bronchus intermedius; LMB, left main bronchus; SQ, squamous cell carcinoma; EMC, epithelial-myoepithelial carcinoma; ACC, adenoid cystic carcinoma.
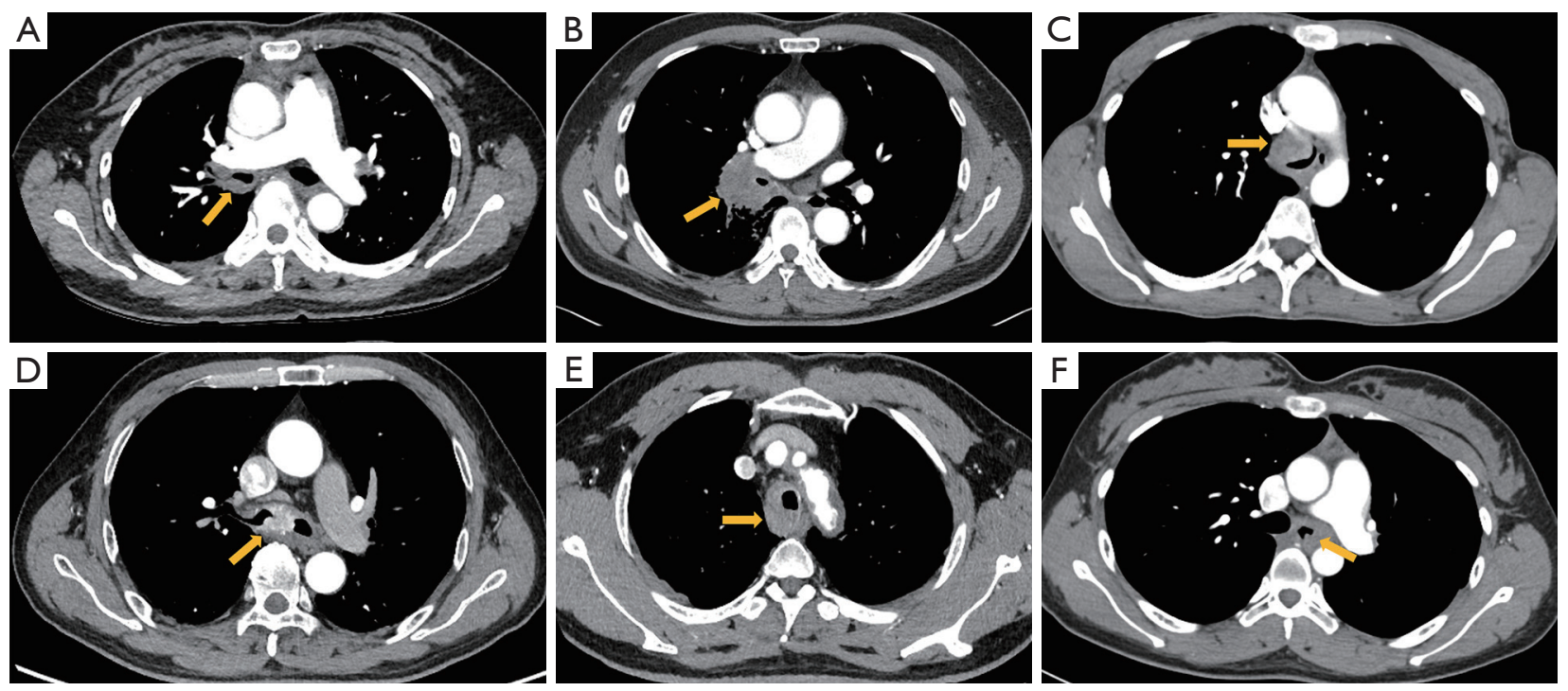

Figure 1 The preoperative CT scan images of the cases. (A) Patient 1 showed a $4 \mathrm{~cm} \times 5 \mathrm{~cm}$ irregular mass in the RMB with hilar and mediastinal lymph node enlargement (yellow arrow); (B) patient 2 showed an $8 \mathrm{~cm} \times 10 \mathrm{~cm}$ broccoli-like tumor in the bronchus intermedius involving the distal RMB (yellow arrow); (C) patient 3 showed a $3.0 \mathrm{~cm}$ irregular mass on the carina involving the orifice of the RMB with mediastinal lymph node enlargement; (D) patient 4 showed a $3.0 \mathrm{~cm}$ irregular mass with a rough and vascularized surface located in the carina. The proximal margin of the tumor was $1.2 \mathrm{~cm}$ above the carina, and the distal margins were $1 \mathrm{~cm}$ and $0.8 \mathrm{~cm}$ from the orifices of the LMB and RMB (yellow arrow); (E) patient 5 showed a longitudinal $3.5 \mathrm{~cm}$ irregular neoplasm involving the right and partial anterior wall of the thoracic trachea $2.5 \mathrm{~cm}$ from the carina (yellow arrow); (F) patient 6 showed an oval mass in the lower trachea measuring $4 \mathrm{~cm}$ longitudinally and involving the carina and the LMB orifice (yellow arrow). CT, computed tomography; RMB, right main bronchus; LMB, left main bronchus. 


\section{Patient 4}

A 62-year-old male presented with an irritative cough and excessive airway excretion for 2 months. The CT scan and bronchoscopy showed a $3.0 \mathrm{~cm}$ irregular mass with a rough and vascularized surface located in the carina. The proximal margin of the tumor was $1.2 \mathrm{~cm}$ above the carina, and the distal margins were $1 \mathrm{~cm}$ and $0.8 \mathrm{~cm}$ from the orifices of the LMB and RMB, respectively (Figure 1D). Subcarinal lymph node enlargement was reported. The pathological result from the biopsy indicated squamous cell carcinoma. The operation was performed using a right thoracotomy with a $0.5 \mathrm{~cm}$ incision in the sixth intercostal space on the right anterior axillary line and a $7 \mathrm{~cm}$ incision in the fourth intercostal space. After the resection and lymphadenectomy, an end-to-end anastomosis was performed between the LMB and the distal stump of the trachea. An end-to-side anastomosis was performed between the RMB and the lateral tracheal wall.

\section{Patient 5}

A 69-year-old male who presented with an irritative cough, DOE, and excessive respiratory excretion attended the clinic for further examination. The CT scan showed a longitudinal $3.5 \mathrm{~cm}$ irregular neoplasm involving the right and partial anterior wall of the thoracic trachea $2.5 \mathrm{~cm}$ from the carina (Figure 1E). PET and CT scan revealed no regional lymph node or distance metastasis. Because the tumor was located in the left tracheal wall and the estimated resection length was relatively long $(>4 \mathrm{~cm})$, the operation was performed via median sternotomy for better surgical vision and complete mobilization of the trachea to minimize the anastomotic tension. A tracheal resection of $4.5 \mathrm{~cm}$ was carried out. The distal RMB was reconnected to the tracheal stump, and an end-to-side anastomosis was conducted between the lateral tracheal wall and the LMB. The pathological result indicated epithelial-myoepithelial carcinoma.

\section{Patient 6}

A 26-year-old female presented with shortness of breath (SOB), DOE, and bloody sputum for 2 months. The chest CT scan revealed an oval mass in the lower trachea measuring $4 \mathrm{~cm}$ longitudinally and involving the carina and the LMB orifice (Figure $1 F$ ). The preoperative bronchoscopy showed that the tumor was lobulated with unclear margins. The lower trachea and the LMB were $60 \%$ and $90 \%$ occluded, respectively. After the sternotomy was completed, the pericardium was opened, and venoarterial extracorporeal membrane oxygenation (VA ECMO) was set up via the femoral vein and the superior vena cava to the ascending aorta. The vessels were mobilized, and the lower trachea, RMB, and LMB were exposed, showing no significant outward invasions. The bilateral hilum and the inferior pulmonary ligaments were thoroughly dissected and divided after opening the mediastinal pleura. Ventilation was not required when the VA ECMO was initiated, and the cardiac preload decreased, so that the lung and heart came smaller and the surgeon could have a better vision and operational space. The involved segments of the trachea, carina, and proximal LMB were resected, and the carina was reconstructed using an end-to-side anastomosis approach (RMB to trachea end-to-end anastomosis and LMB to trachea end-to-side anastomosis). The thymus was used for the anastomotic buttress. Chest tubes were placed in her bilateral thoracic cavities because her mediastinal pleura was open.

\section{Surgical technique}

The end-to-side procedure can be chosen according to the surgeon's preference and the actual surgical conditions. The following issues should be considered in advance to facilitate end-to-side anastomosis. First, if the surgeons are intending to use both anastomotic methods, the endto-side anastomosis should be performed after the end-toend procedure. End-to-end anastomosis is generally more straightforward, and the lateral implantation position will be determined according to the end-to-end anastomosis (7). Second, the transactional area of the hosting airway (trachea or bronchus) should be large enough for implantation. The fenestration on the lateral wall of the trachea or hosting bronchus should be trimmed to fit the opening of the implanting bronchus. In addition, the opening should not be too close to the end-to-end anastomosis to avoid stitches kinking or jeopardizing the anastomosis. The opening should be made entirely on the cartilage wall of the trachea (6). The implanting bronchus should be sectioned to include less than $5 \mathrm{~mm}$ before its segmental bifurcation or trifurcation. This effectively avoids stitches kinking, excessive tension, and ischemia on the membranous wall (Figure 2A-2C).

The parachute principle is recommended in the anastomosis process. A 3-0 or 4-0 double-ended Prolene suture (Ethicon Inc., Somerville, NJ, USA) should be used. The stitch is placed on the graft or hosting bronchus from the inside wall approximately $0.5 \mathrm{~cm}$ from the margin. 

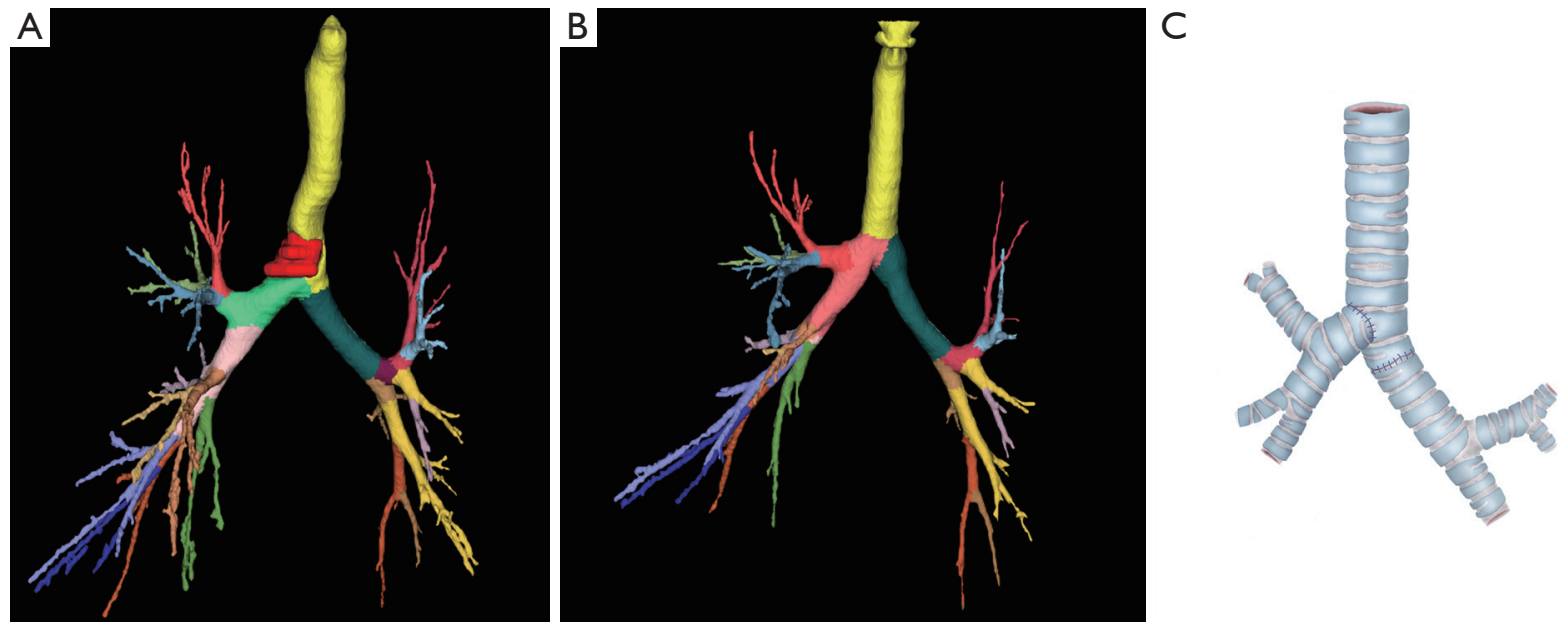

Figure 2 The three-dimensional model and diagram of Patient 3. (A) The tracheobronchial tree three-dimensional model of Patient 3 demonstrating an irregular mass located in the lower trachea involving the carina and partial RMB; (B) the postoperative three-dimensional model of Patient 3 after end-to-side airway reconstruction; (C) the diagram of the reconstruction of Patient 3 (trachea-LMB end-to-end anastomosis and trachea-RMB end-to-side anastomosis). RMB, right main bronchus; LMB, left main bronchus.

When half of the anastomosis is finished, the second half can proceed with the other end of the suture. The cartilage wall should be sutured first, followed by the membranous wall to balance anastomotic disparities. Once all the stitches have been placed, the suture can be approximated using the parachute method with nerve hooks and kept on traction. Then it is pulled tight with the tracheobronchial mucosa turned inward to facilitate recovery. The anastomosis is then tested for air leaks to $35 \mathrm{mmHg}$. Interrupted sutures with 4-0 Monocryl (Ethicon Inc.) are commonly used to repair the anastomosis if any air leak is noticed.

Anastomosis with interrupted sutures using 4-0 Vicryl (Ethicon Inc.) is also feasible. The principle is the same as that of continuous sutures in that the membranous wall should be sutured and tied with knots outside the airway. Di Rienzo and his colleagues reported that when performing an end-to-side anastomosis, the cartilage wall can be reconnected first with a continuous suture using 3-0 or 4-0 double-ended PDS (Ethicon Inc.), then fixed with 2 separate PDS sutures of the same size on both edges (6). Interrupted 3-0 to 5-0 Vicryl sutures can be used to reconstruct the membranous wall. Finally, a circumferential buttress on the tracheal anastomosis is highly recommended. The strap muscle and thyroid gland are usually used as the buttress for the cervical trachea. The sternocleidomastoid muscle can be used if the strap muscle is unavailable in some reoperative cases. The mediastinal tissues, including mediastinal pleural flap and thymic flap, are feasible for the thoracic trachea buttress (8). In some long-defect tracheobronchial reconstruction cases, the omentum majus can be dissected, relocated to the thoracic cavity from the abdomen through the diaphragm, and used as the buttress (9).

The current study was conducted in accordance with the Declaration of Helsinki (as revised in 2013). The six patients were identified from the patients who had received the tracheobronchial resection and reconstruction in the Department of Thoracic Surgery from the First Affiliated Hospital of Guangzhou Medical University. The study was approved by the Ethics Committee of the First Affiliated Hospital of Guangzhou Medical University (No. 2020K43), and the informed consents for this retrospective analysis was attained from the included patients.

\section{Results}

The mean operation time was 316 minutes, while the total average blood loss was $160 \mathrm{ml}$ without blood transfusion. The patients were discharged within 14 days of the operation with no significant short-term complications. They were administered adjuvant chemotherapy and advised to receive a chest CT scan every 3 months and a bronchoscopy every 6 months. During the follow-up, there was no sign of local tumor recurrence, new lesions, or distant metastasis.

Patients 1 and 2 were on ventilators in the ICU and administered anticoagulation medications on postoperative 
day 2 (POD 2). They were extubated on POD 5 and transferred to the general ward on POD 6 and 7. The patients were eventually discharged on POD 14 presented with mild irritative cough after exercise. Neither dyspnea nor other symptoms were observed. On POD 10, the bronchoscopy of Patient 1 showed circumferential swelling on the anastomosis and some purulent excretion but no anastomotic necrosis. A higher grade of antibiotic was prescribed. After 3 days, an exam showed no significant narrowing or occlusion. The patients' symptoms were significantly alleviated after the administration of antitussives and antiasthmatics. No oncological or anastomotic complications were reported during the followup (Figure 3A,3B).

Patients 3, 4, and 5 received general anesthesia with endotracheal tubes and were extubated in the postanesthetic care unit (PACU). They stayed in the ICU for an average of 4 days before transferring to the general ward and were discharged within 10 days of the operation. Antibiotics were administered for 4 to 6 days, and the patients' chest tubes were removed on POD 3 or 4 . The CT scan and bronchoscopy showed an unobstructed, well-recovered anastomosis without ischemic change, stenosis, or fistula.

Patient 6 was successfully detached from ECMO after the tracheal reconstruction with stable hemodynamic status. She was on mechanical ventilation for 5 days in the ICU because of hypercapnia and was transferred to the general ward on POD 8 after extubation. The involved tracheal segment $(2.5 \mathrm{~cm})$ and the proximal segment of the LMB $(3 \mathrm{~cm})$ were resected and confirmed as adenoid cystic carcinoma. The patient's chest tubes were removed on POD 3 and 4 with satisfying lung reinflation. A postoperative bronchoscopy on POD 3 showed no necrotic change or dehiscence in the anastomosis. But the anastomosis was swelling, and some purulent secretion could be seen in the distal LMB. Carbapenem and albumin were administered, and a subsequent bronchoscopy was conducted for excretion removal. The patient was discharged on POD 12 without postoperative complications. The bronchoscopy before discharge showed no purulence or other abnormalities.

During the follow-up (6-15 months), no wheezing, refractory irritative cough, DOE, or fistula was found in Patients 3 to 6.

\section{Discussion}

Interrupted suture and continuous suture using the parachute technique are both feasible options for end-to- side anastomosis depending on the surgeon's preference. Each technique has merits and defects. The parachute technique continuous suture is reported to be quicker, and less traumatic, and it is easier to perform with direct anastomotic visualization. However, extra stitches may be needed if the continuous suture is not tight enough or is broken. Therefore, this technique is suitable for experienced surgeons. Although the interrupted suture technique requires more stitches and sutures, it is more beginner-friendly and is easy to adjust when the stitches are kinking.

Compared to the end-to-end anastomosis approach, the end-to-side approach allows customization of the hosting trachea or lateral bronchus orifice for reimplantation without oblique trimming of the implanting bronchus. However, the hosting trachea or bronchus should be devascularized and dissected to create a lateral wall for reconnection which might lead to blood flow distortion and necrosis. In addition, the end-to-side approach has been reported to cause angulation of the implanted bronchus and further increase the tension of the anastomosis. Some studies have shown that turbulence might be generated when air flows through the bronchus at steep angles $(10,11)$.

Regarding hosting the airway, previous study has reported that the trachea is not suitable for hosting the bronchus intermedius, as there is a high risk of necrosis (6). Therefore, the authors suggested that the LMB might be safer for implantation, although this procedure was complex and technically demanding (6).

A lack of tension and the preservation of the blood supply are the keystones for anastomosis. Sufficient and suitable mobilizations are therefore recommended, including release maneuvers involving the hilum, pericardium, pulmonary ligament, and larynx (12). The blood supplies of the cervical and thoracic trachea are various. The tracheoesophageal branches of the inferior thyroid artery supply blood to the cervical trachea, while the bronchial artery arising from the aorta supplies the thoracic trachea, carina, and bronchus. These arteries carry blood to the trachea in a segmental pattern along its longitudinal access, branching superiorly and inferiorly as they reach the lateral tracheal wall and forming anastomoses with the segmental arteries above and below (13). In contrast, the bronchus blood supply is carried by the bronchial arteries from the aortic branches. Therefore, tracheal anastomosis is more vulnerable to ischemia than bronchial anastomosis is. Excessive vascularization of the airway is reported to jeopardize the blood supply (14). Thus, the surrounding tissue should not 

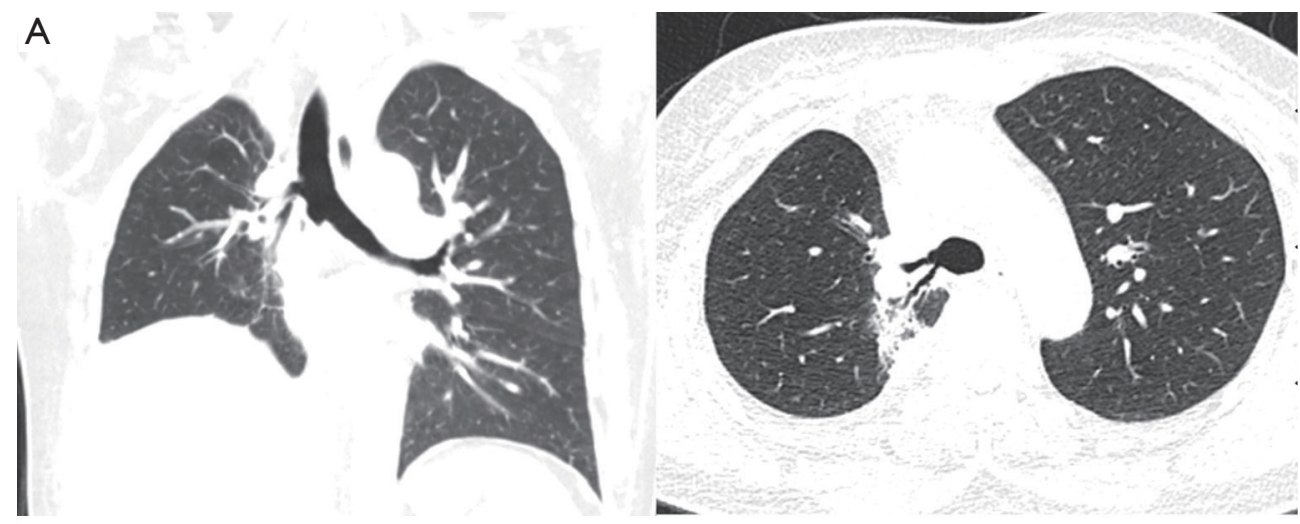

B
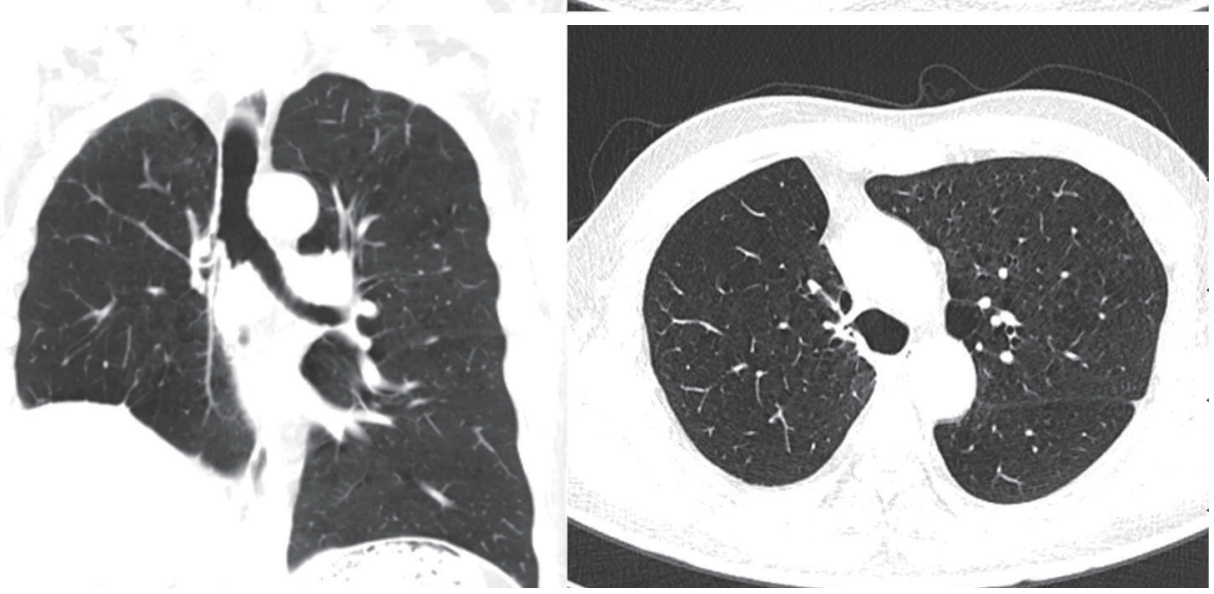

Figure 3 The postoperative CT scan of Patients 1 and 2. (A) Patient 1 received an end-to-side anastomosis via right basal segment stump and lateral tracheal wall. The graft is well inflated without anastomotic stenosis or airway occlusion; (B) Patient 2 received an end-to-side anastomosis via right lower lobe bronchial stump and lateral tracheal wall. The graft is well inflated without anastomotic stenosis or airway occlusion.

be dissected more than $0.5 \mathrm{~cm}$ from the anastomosis. The anastomotic buttressing is highly recommended.

The most commonly seen complication of end-toside anastomosis was the temporary anastomotic stenosis which was probably because of postoperative tissue edema, inflammation or infection. The most serious complication would be anastomotic dehiscence, which could be fatal. In order to prevent these complications, the tensionfree anastomosis is really crucial. Various methods can be applied to minimize the risk of the complications including suitable mobilization of the trachea, additional release maneuver, suturing technique, suture types, anastomotic method, and etc. In the current study, we described endto-side anastomosis which was one of the methods. The treatments of these complications are as follow: (I) higher grade of antibiotics; (II) routine bronchoscopy for excretion removal; (III) albumin; (IV) mechanical ventilation with lower positive end-expiratory pressure (PEEP). Most of the patients would ameliorate after these measures without secondary operation for anastomosis repair.

\section{Conclusions}

End-to-side anastomosis is a feasible approach for complex tracheobronchial reconstruction. As the superiority of different anastomotic methods has not been completely clarified, surgeons can select which method to use depending on the operation and their own preferences.

\section{Acknowledgments}

Funding: None. 


\section{Footnote}

Reporting Checklist: The authors have completed the AME Case Series reporting checklist. Available at https://tlcr. amegroups.com/article/view/10.21037/tlcr-22-32/rc

Data Sharing Statement: Available at https://tlcr.amegroups. com/article/view/10.21037/tlcr-22-32/dss

Conflicts of Interest: All authors have completed the ICMJE uniform disclosure form (available at https://tlcr.amegroups. com/article/view/10.21037/tlcr-22-32/coif). The authors have no conflicts of interest to declare.

Ethical Statement: The authors are accountable for all aspects of the work in ensuring that questions related to the accuracy or integrity of any part of the work are appropriately investigated and resolved. The study was conducted in accordance with the Declaration of Helsinki (as revised in 2013). The study was approved by the Ethics Committee of the First Affiliated Hospital of Guangzhou Medical University (No. 2020K-43), and informed consents for this retrospective analysis was attained from the included patients.

Open Access Statement: This is an Open Access article distributed in accordance with the Creative Commons Attribution-NonCommercial-NoDerivs 4.0 International License (CC BY-NC-ND 4.0), which permits the noncommercial replication and distribution of the article with the strict proviso that no changes or edits are made and the original work is properly cited (including links to both the formal publication through the relevant DOI and the license). See: https://creativecommons.org/licenses/by-nc-nd/4.0/.

\section{References}

1. Grillo HC, Mathisen DJ. Primary tracheal tumors: treatment and results. Ann Thorac Surg 1990;49:69-77.

2. Gaissert HA, Grillo HC, Shadmehr MB, et al. Longterm survival after resection of primary adenoid cystic and squamous cell carcinoma of the trachea and carina. Ann

Cite this article as: $\mathrm{He} \mathrm{J}, \mathrm{Xu} \mathrm{X}$, Lan L, Chen $\mathrm{H}, \mathrm{He} \mathrm{J}$, Li S. End-to-side anastomosis in complex tracheal resection and reconstruction: a case series study. Transl Lung Cancer Res 2022;11(2):165-172. doi: 10.21037/tlcr-22-32
Thorac Surg 2004;78:1889-96; discussion 1896-7.

3. Shai SE, Wang LL, Hung SC. Curing a Patient of Recurrent Tracheal Papillomatosis Using Laser Ablation and Adjuvant Radiotherapy. Ann Thorac Surg 2020;110:e91-3.

4. Nam SJ, Oak CH, Jang TW, et al. Successful treatment of a tracheal squamous cell carcinoma with a combination of cryoablation and photodynamic therapy. Thorac Cancer 2013;4:191-4.

5. Costantino CL, Geller AD, Wright CD, et al. Carinal surgery: A single-institution experience spanning 2 decades. J Thorac Cardiovasc Surg 2019;157:2073-2083.e1.

6. Di Rienzo G, Go T, Macchiarini P. Simplified anastomotic technique for end-to-side bronchial reimplantation onto the trachea or contralateral main bronchus after complex tracheobronchial resections. J Thorac Cardiovasc Surg 2002;124:632-5.

7. Schröder C, Vogel B, Krause J, et al. Tracheal reimplantation of the right upper lobe bronchus with sleeve main and intermedius bronchus resection and reconstruction. J Thorac Cardiovasc Surg 2001;121:388-90.

8. Wright CD, Li S, Geller AD, et al. Postintubation Tracheal Stenosis: Management and Results 1993 to 2017. Ann Thorac Surg 2019;108:1471-7.

9. Chen J, Ang KL, Wang C, et al. Minimally invasive carinal reconstruction using bronchial flap and omental flap reinforcement. Ann Thorac Surg 2021. [Epub ahead of print].

10. Gu Q, Qi S, Yue Y, et al. Structural and functional alterations of the tracheobronchial tree after left upper pulmonary lobectomy for lung cancer. Biomed Eng Online 2019;18:105.

11. Qi S, Zhang B, Yue Y, et al. Airflow in Tracheobronchial Tree of Subjects with Tracheal Bronchus Simulated Using CT Image Based Models and CFD Method. J Med Syst 2018;42:65.

12. Broussard B, Mathisen DJ. Tracheal release maneuvers. Ann Cardiothorac Surg 2018;7:293-8.

13. Furlow PW, Mathisen DJ. Surgical anatomy of the trachea. Ann Cardiothorac Surg 2018;7:255-60.

14. Minnich DJ, Mathisen DJ. Anatomy of the trachea, carina, and bronchi. Thorac Surg Clin 2007;17:571-85. 